\title{
The Effects of Regolith-Landform Development in Diamond Exploration: a Spectral Investigation
}

Harris, P.D., and Courtnage, P.M.

Geophysical Services Department, Anglo American Corporation of S.A. Limited, 45 Main Street, Johannesburg, 2001

The regolith, which is defined as 'The entire layer or mantle of fragmental and loose material, incoherent, or unconsolidated rock material, of whatever origin (residual or transported), and of varied character, that nearly everywhere forms the surface of the land and overlies or covers the more coherent bedrock' (Gary et al, 1972), strongly influences surficial sampling methods in diamond exploration. Understanding of the regolith-landform development forms an important component in evaluating the most suitable exploration technique to be applied for diamond exploration within an individual terrain. Knowledge of the regolith-landform and the processes involved in its formation also enable a better interpretation of results obtained from various exploration techniques. Areas with transported overburden on prospective terrains are not suited for surficial exploration techniques such as geochemical soil sampling. Likewise a different interpretation has to be placed on heavy mineral results obtained from the transported overburden. A rapid method to evaluate the regolith-landform development over large areas of interest is required if it is to be used successfully. A method suitable for this evaluation would be TM imagery, which provides spectral characteristics of the land surfaces. In order to understand the full implications of the different TM spectral responses, an understanding of the controls of these responses, and hence regolith development, is required. To achieve this, different regolith units have been evaluated in terms of their development conditions, geomorphological setting, mineralogy and spectral response. Changes and characteristic mineralogical signatures and field spectral responses within the regolith profile are discussed within this manuscript.

During this investigation portable field spectrometers were used, which record the spectral response within the near-infrared (NIR) and short wave infrared (SWIR) wavelength ranges (Hunt and Ashley, 1979 and associated references). These instruments have been used to characterise the spectral responses of different regolith units. Minerals typically detected by these instruments are oxides, clays, carbonates, sulphates and other minerals exhibiting hydroxyl bonds such as micas and amphiboles. In the SWIR wavelength range subtle changes in mineral structures can be detected through wavelength shifts, and spectral or absorption shape changes. Changes in the chemistry or crystal ordering of a mineral can also be distinguished through changes in the spectral responses. Certain polytypes can be recognised and distinguished fairly rapidly using the field portable spectrometers (Hauff et al, 1989). It is these types of features that are of interest when evaluating the spectral responses of different regolith material.

Several factors have an important influence on the development of the regolith and hence influence the spectral signatures obtained from the different units. The five main factors are:

-. Climate

- Nature of parent rock

- Landscape/topography and drainage

- Mechanical activity

- Time 
Climatic conditions have an important control on the development of the regolith as temperature and precipitation influence the rates of the chemical and physical processes responsible for the profile development. In areas subjected to seasonal high rainfall, succeeded by arid conditions, large fluctuations in the water table occur subsequently leaching the regolith profile (Schirrmeister and Storr, 1994). The landscape/topography also influences the rates of the weathering processes as certain land surfaces are more suited for soil development than others. Areas of good drainage are more strongly leached than those of poor drainage. Mechanical activity such as wind, water, gravity and living organisms all have an influence on the development of the regolith. Bioturbation recycles material within the profile and changes in vegetation type, and distribution, have significant effects on the regolith. The nature of the parent rock also has a pronounced effect on the mineralogy and crystal structure of the secondary mineral phases. Through time, however, the effects of the parent material are diminished. Time influences the maturity of the soils and hence also controls some of the characteristics and development of the regolith. The mineralogy, and hence spectral responses, of the different regolith units are therefore directly controlled by the above factors. An understanding of the relationship between the factors controlling the regolith development and the resultant nature of the specific unit assists in the selection of the most suitable exploration method.

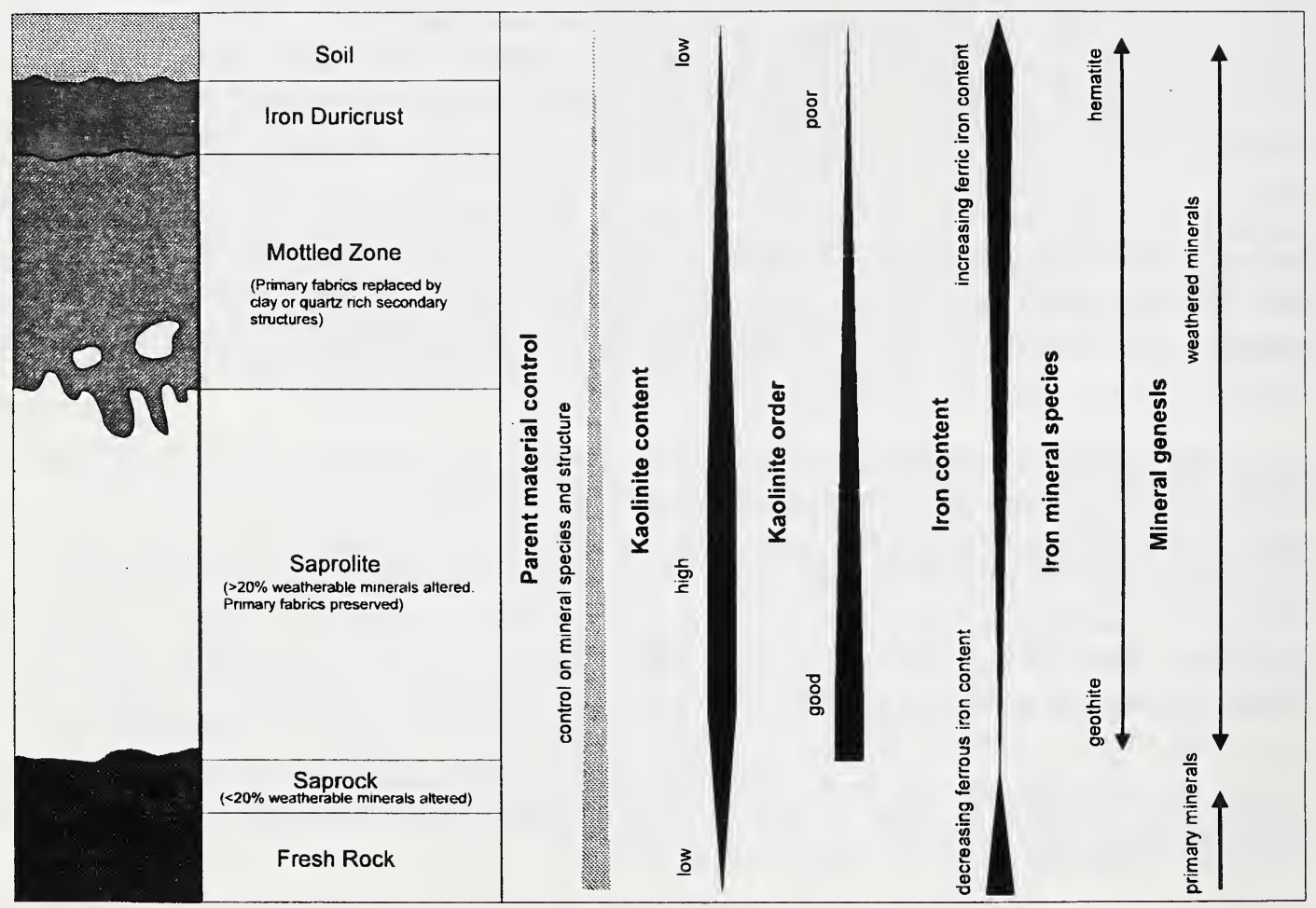

Figure 1. A modified model of weathering development in the regolith profile.

In regions where lateritisation is an important process, deeply weathered profiles are developed. Iron duricrust is commonly formed in these terrains and a typical lateritic profile is developed. A model of a typical lateritic weathering profile is shown in the accompanying diagram. In this diagram the types, and relationships between different regolith units are displayed. A model of the changing weathering mineralogy, based specifically on minerals and changes that can be detected 
spectrally, are also displayed on this diagram. Signatures of the original parent material are preserved within the primary or secondary minerals in the lower, less weathered regolith units. Crystal structures are influenced by the original mineralogy, and the ordering of certain minerals such as kaolinite are strongly influenced by the original parent material Zeese et al, 1994). Kaolinite content initially increases higher in the regolith profile, but then decreases within the upper units where it is replaced by oxides and hydroxides as iron and aluminium are concentrated (Calvert et al, 1980). Kaolinite ordering tends to decrease upwards in the profile but the relative ordering tends to be more strongly controlled by the original parent material. Ferrous iron content decreases as the fresh rock is weathered and the ferric iron content is concentrated towards the iron duricrust. Iron mineral species also change through the different regolith units.

All these mineralogical changes have distinct spectral characteristics that can be detected through the use of field portable spectrometers (Hunt and Salisbury, 1970). Estimates of kaolinite abundance can be made using the absorption depths of features characteristic to kaolinite. Kaolinite ordering is represented by changes in the response of doublet absorption features typical for this mineral (Crowely and Vergo, 1988). Likewise, the oxide species and iron content can be estimated from spectral information through absorption depths and wavelength changes of the characteristic absorption features. These changes in spectral responses can assist in the interpretation of the regolith within different regions.

Changes in regolith-landform development can therefore be detected through changes in the spectral responses of the different material. The interpretation of the regolith unit from the spectral response is, however, complicated by several factors. Changes in the underlying lithologies may influence the response, producing different units or regimes with similar spectral signatures. Similarly, differences of soil maturity within the area of interest will effect the spectral response and complicate the interpretation. Nonetheless differences within the profile will be detected spectrally, but associating spectral responses to different regolith-landforms remains complicated. Further work is required to refine and test these observations in different terrains.

\section{References}

Crowely, J.K., nad Vergo, N., 1988, Near-infrared reflectance spectra of mixtures of kaolin-group minerals: use in clay mineral studies. Clays and Clay Minerals, 91, 5001-5012.

Gary, M., McAfee, R. Jr., and Wolf, C.L. 1972, Glossary of Geology. American Geological Institute, Washington, D.C., 803p.

Hunt, G.R., and Ashely, R.P., 1979, Spectra of altered rocks in the visible and near infrared. Economic Geology, 74, 1613-1629.

Hunt, G.R., and Sailsbury, J.W., 1970, Visible and near infrared spectra of minerals and rocks. I. Silicate minerals. Modern Geology, 1, 283-300.

Schirrmeister, P., and Storr, M., 1994, The weathering of basaltic rocks in Burundi and Vietnam. Catena, 21, 243-256.

Zeese, R., Schwertmann, U., Tietz, G.F., and Jux, U., 1994, Mineralogy and stratigraphy of three deep laterite profiles of the Jos Plateau (Central Nigeria). Catena, 21, 195-214. 